\title{
APRESENTAÇÃO
}

\section{A FORMAÇÃO BARREIRAS: RECENTES AVANÇOS E ANTIGAS QUESTÕES}

Este número da revista Geologia USP - Série Científica é dedicado à Formação Barreiras, constituindo uma coletânea de trabalhos apresentados no simpósio "Significado Geológico da Formação Barreiras", ocorrido em Guarapari (ES) em outubro de 2005, como parte da programação do X Congresso da Associação Brasileira de Estudos do Quaternário (ABEQUA). Ao pesquisar sobre este tema, ou com diversos aspectos geológicos a ele relacionados, durante vários anos (alguns de nós desde nossa formação acadêmica), sentíamos a necessidade de um encontro científico que reunisse pesquisadores para debatê-lo de forma integrada. Esta preocupação nos levou a propor um simpósio para discutir o significado desta unidade estratigráfica, o primeiro dedicado exclusivamente ao seu estudo. O perfil dos pesquisadores e o local de realização nos indicaram que o X ABEQUA seria o fórum adequado para este encontro.

Descrever a evolução do conhecimento sobre a Formação Barreiras é igualmente descrever o conhecimento da evolução das ciências geológicas no Brasil. A Formação Barreiras foi a primeira unidade estratigráfica documentada no Brasil, por ocasião da redação da carta de Pero Vaz de Caminha ao Rei de Portugal, D. Manoel I. Esta unidade estende-se ao longo do litoral brasileiro, desde o Rio de Janeiro até o estado do Amapá, recobrindo depósitos sedimentares mesozóicos de diversas bacias costeiras. Este é o substrato sobre o qual se desenvolve a maior parte do Quaternário costeiro no Brasil. A porção do litoral onde esta unidade ocorre é, na sua maioria, intensamente povoada. $O$ seu uso constante na extração de bens minerais, bem como de água subterrânea, tem exigido melhor conhecimento de seus diversos aspectos.

Várias questões, relacionadas à Formação Barreiras, que são tratadas neste número, ainda persistem. Muitos estudos têm contribuído para entender a diversidade de processos e ambientes sedimentares, mas muito ainda deve ser feito para identificar e caracterizar estas variações. A idade da Formação Barreiras tem sido atribuída ao intervalo de tempo que varia do Mioceno até o Plioceno-Pleistoceno. Grande parte destas idades, entretanto, foram vagamente inferidas a partir de interpretações geomorfológicas e paleoclimáticas. Apenas mais recentemente estudos palinológicos e radiométricos apontam para uma idade miocênica. Mas, devido à sua grande 
distribuição e variação espacial, outras idades devem ser obtidas. Estudos têm demonstrado que esta unidade sofreu considerável deformação tectônica. Estes trabalhos mostram o risco do uso de feições geomorfológicas isoladamente para sua caracterização e os possíveis problemas para o seu mapeamento geológico. Finalmente, muitos problemas são provocados pelo excesso de denominações estratigráficas informais.

Nota-se, portanto, que as abordagens regionais e generalizações feitas sobre a Formação Barreiras são problemáticas. O relativo desconhecimento de diversos aspectos está exigindo uma revisão de muitos mapas desta unidade.

Neste número especial, aspectos deposicionais e tectônicos da Formação Barreiras são descritos. Os trabalhos tratam de vários trechos do litoral brasileiro e abrangem pelo menos sete estados. Os artigos estão organizados em dois grupos. O primeiro contém cinco trabalhos e trata principalmente dos aspectos deposicionais, como ambientes e sistemas deposicionais, fácies sedimentares e características estratigráficas. O segundo contém três trabalhos que descrevem principalmente as deformações tectônicas na geração de estruturas e formas de relevo.

Durante muito tempo, a Formação Barreiras era considerada de origem essencialmente continental. Entretanto, mais recentemente, os trabalhos têm mostrado a influência de oscilações eustáticas na sua origem e deposição até em ambientes transicional e marinho raso. Os dois primeiros trabalhos deste número especial, desenvolvidos no norte e nordeste do Brasil, tratam desta questão e apresentam elementos que possibilitam correlações estratigráficas regionais.

O trabalho de Mitsuru Arai mostra a evolução desta unidade em associação com as variações eustáticas do Mioceno. Para tanto, o autor usa datações palinológicas e correlações estratigráficas realizadas principalmente no norte do país. Este trabalho sugere a existência de discordância erosiva de grande importância para correlações estratigráficas. $\mathrm{O}$ autor ainda sugere a classificação desta unidade como grupo, composto por uma subunidade superior e outra inferior, separadas por esta discordância.

O trabalho de Dilce Rossetti, que trata da Formação Barreiras nos estados do Pará e Maranhão, identifica fácies sedimentares carbonáticas e siliciclásticas que foram interpretadas como de ambientes marinhos rasos e litorâneos, limitadas por descontinuidades. Estas superfícies seriam mapeáveis em escala regional e serviriam para correlação estratigráfica. Aliada à influência eustática, esta autora ainda sugere a existência de controle tectônico associado à sedimentação desta unidade, em vales estuarinos. 


\section{Geologia \\ serecerentrita g USP}

Normalmente, os sistemas deposicionais da Formação Barreiras têm sido associados a leques aluviais e fluviais entrelaçados, acompanhados de freqüentes depósitos gravitacionais. Os dois trabalhos seguintes descrevem bem esta deposição continental.

artigo de Morais et al. descreve associações de fácies sedimentares no litoral fluminense, onde ainda existem poucos trabalhos de pesquisa sobre o tema. Os autores sugerem diferentes modelos fluviais entrelaçados, com participação importante de fluxos gravitacionais. Da mesma forma que no trabalho precedente, os autores concluem que mecanismos tectônicos sin-sedimentares também teriam controlado a sedimentação.

O trabalho de Santos et al. usa nova tecnologia na caracterização dos depósitos sedimentares da Formação Barreiras nos litorais norte do Rio de Janeiro e sul do Espírito Santo. Eles apresentam o uso do georradar (em inglês Ground Penetrating Radar, GPR) na determinação da arquitetura deposicional desta unidade, que é confrontada com descrições de afloramentos. Trata-se de uma contribuição interessante de uso de novas tecnologias em estudos de depósitos neogênicos em subsuperfície.

Variações importantes nos ambientes de deposição são sugeridas no quinto trabalho deste primeiro grupo. Araújo et al. descrevem fácies siliciclásticas que teriam sido depositadas em um sistema fluvial meandrante. Esta interpretação está baseada em descrição faciológica de excelentes exposições no litoral do Rio Grande do Norte, e ilustra a diversidade de ambientes deposicionais desta unidade.

O segundo grupo de trabalhos descreve, de forma mais detalhada, movimentos neotectônicos que afetaram esta unidade. No trabalho de Nogueira, Bezerra e Castro é investigada a deformação dos depósitos descritos por Araújo e outros no litoral do Rio Grande do Norte. Os primeiros autores apresentam mapas de isópacas e de contorno estrutural da base da unidade, que mostram significativas variações de espessura e de altitude do pacote sedimentar. Estas variações são geralmente bruscas e estão condicionadas por falhas. Os autores concluem que esta deformação foi induzida por dois campos de tensões tectônicas sucessivos.

Os tabuleiros litorâneos, típicos da Formação Barreiras, têm sido descritos como uma feição geomorfológica não deformada. Nos dois trabalhos seguintes, é analisado o comportamento destas feições geomorfológicas. Parâmetros como altitude, orientação e padrão de drenagem, além de nível de erosão, são usados para identificar blocos tectônicos. 
O trabalho de Furrier, Araújo e Meneses trata das relações entre geomorfologia e tectônica, conforme observações feitas na faixa sedimentar costeira do Estado da Paraíba, onde tabuleiros litorâneos apresentam variações de altitude e nível de erosão. As transições são bruscas e estão delimitadas por falhas e basculamento de blocos.

No artigo de Lima, Vilas Boas e Bezerra, no litoral sul do Estado da Bahia, são igualmente identificadas superfícies de tabuleiros com diferentes padrões e orientações de drenagem associados a falhas. Os autores, através destes padrões, identificam três sentidos de basculamento de blocos. De forma similar ao trabalho de Morais et al. no Estado do Rio de Janeiro, estes autores descrevem uma associação de fácies de sistema fluvial entrelaçado.

Os editores esperam que este número especial sirva de estímulo às pesquisas da diversidade desta unidade e para embasar as integrações regionais. Esperam também que os trabalhos aqui apresentados contribuam para a exploração ordenada dos recursos naturais ligados à Formação Barreiras.

\section{Agradecimentos}

A coordenação deste volume temático da Geologia USP agradece aos autores dos artigos, aos relatores anônimos, ao Conselho Editorial desta revista e, de forma especial, ao Prof. Dr. Thomas Rich Fairchild, do Instituto de Geociências da USP, pelas pertinentes sugestões nas correções dos Abstracts.

\section{Francisco Hilário Rego Bezerra}

bezerrafh@geologia.ufrn.br Departamento de Geologia - CCET - UFRN, Natal, RN

\section{Claudio Limeira Mello}

limeira@geologia.ufri.br

Departamento de Geologia - IGEO/CCMN - UFRJ, Rio de Janeiro, RJ

\section{Kenitiro Suguio}

Departamento de Geologia Sedimentar e Ambiental - IGc - USP, São Paulo, SP

Centro de Pós-Graduação, Pesquisa e Extensão - UnG, Guarulhos, SP 